\title{
FAKTOR-FAKTOR YANG BERHUBUNGAN DENGAN STATUS GIZI PADA BALITA USIA 6-23 BULAN DIKELURAHAN PANTOLOAN BOYA WILAYAH KERJA PUSKESMAS PANTOLOAN
}

\author{
Abd. Farid Lewa \\ Politeknik Kesehatan Kementerian Kesehatan Palu
}

\begin{abstract}
ABSTRAK
Indonesia menghadapi masalah gizi ganda, yaitu masalah gizi kurang dan masalah gizi lebih. Hasil riskesdas, secara nasional pada tahun 2013 menunjukan prevalensi status gizi anak balita menurut (BB/U) yaitu prevalensi gizi buruk sebesar 5,7\%, dan gizi kurang 13,9\%. Di kota palu tahun 2013 prevalensi status gizi anak balita menurut (BB/U), yaitu prevalensi gizi buruk sebesar $6,6 \%$, dan gizi kurang $17,5 \%$.sedangkan di Puskesmas Pantoloan tahun 2014 prevalensi status gizi anak balita menurut (BB/U) yaitu prevalensi gizi kurang sebesar 9,7\%, gizi buruk 3,9\%, dan gizi lebih $4,1 \%$.Penelitian ini bertujuan untuk mengetahui hubungan pendidikan, pekerjaan dan pengetahuan ibu tentang Makanan Pendamping ASI dengan status gizi balita usia 6-23 bulan di kelurahan Pantoloan Boya Wilayah Kerja Puskesmas Pantoloan.

Desain penelitian yang digunakan adalah analitik dengan metode crossectional dan pengambilan data menggunkan data primer. Populasi dalam penelitian ini adalah seluruh ibuyang memiliki balita umur 6-23 bulan,dilakukan di Posyandu kelurahan Pantoloan Boya wilayah kerja Puskesmas Pantoloan pada bulan Mei-Juni 2015. Sampel dalam penelitian ini menggunakan tehnik accidental sampling yaitu responden yang kebutulan ada atau tersedia disuatu tempat yang berjumlah 76 balita.

Hasil penelitian menggunakan uji fisher's exact menunjukkan bahwa nilai p-value sebesar 0,145 > 0,05 untuk pendidikan , $p=0,075$ ( $p$ value $>0,05$ ) untk pekerjaan, berarti secara statistik tidak ada hubungan antara pendidikan, pekerjan ibu dengan status gizi balita, sedangkan dari hasil uji fishes'r exact didapatkan nilai $p=0,000$ ( $p$ value $<0,05$ ) artinya secara statistic ada hbungan pengetahuan ibu dengan status gizi balita umur 6-23 bulan di puskesmas Pantoloan Kecamatan Tawaeli Tahun 2015.

Kesimpulandalam penelitian ini adalah tidak ada hubungan pendidikan ibu dan pekerjaanibu namun ada hubungan yang bermakna antara pengetahuan lbu tentang Makanan Pendamping ASI dengan Status Gizi pada balita usia6-23 bulan di kelurahan Pantoloan Boya Wilayah Kerja Puskesmas Pantoloan.Kepada Petugas Puskesmas Pantoloan agar dapat menjadi sarana penyelenggara penyuluhan kepada ibu tentang Makanan Pendamping ASI.
\end{abstract}

Daftar Pustaka : 16 (2000-2013)

Kata kunci : Pendidikan, Pekerjaan, Pengatahuan, Status Gizi

\section{PENDAHULUAN}

Indonesia menghadapi masalah gizi ganda, yaitu masalah gizi kurang dan masalah gizi lebih.Masalah gizi kurang pada umunya disebabkan oleh kemiskinan, kurang persediaan pangan, kurang baiknya kualitas lingkungan (sanitasi), kurangnya pengetahuan masyarakat tentang gizi, menu seimbang dan kesehatan, adanya daerah miskin gizi (iodium).Sebaliknya masalah gizi lebih disebabkan oleh kemajuan ekonomi (Almatsier, 2009).

Menurut World Health Organization (WHO) lebih dari $50 \%$ kematian bayi dan anak terkait dengan gizi kurang dan gizi buruk. Oleh karena itu masalah gizi perlu di tangani secara cepat dan tetap.Keadaan inilah yang berpengaruh 
pada tingginya angka kematian bayi (Kemenkes, 2011).

Hasil survei menunjukkan bahwa salah satu penyebab terjadinya gangguan tumbuh kembang bayi dan anak usia 6 sampai 24 bulan di Indonesia adalah rendahnya mutu MP-ASI (makanan pendamping ASI) dan ketidak sesuaian pola asuh yang diberikan sehingga beberapa zat gizi tidak dapat mencukupi kebutuhan energi dan zat mikro terutama zat besi (Fe) dan Seng (Zn). Pemberian makanan adalah salah satu faktor yang mempengaruhi status gizi bayi. Pemberian makanan yang kurang tepat dapat menyebabkan terjadinya kekurangan gizi dan pemberian yang berlebihan akan terjadi kegemukan. Pada usia 6 bulan, secara fisiologis bayi telah siap menerima makanan tambahan, karena secara keseluruhan fungsi saluran cerna sudah berkembang. Selain itu, pada usia tersebut Air Susu Ibu (ASI) sudah tidak lagi mencukupi kebutuhan energy bayi hanya sekitar 65-80\% kebutuhan bayi, dan sangat sedikit mengandung mikronutrien untuk tumbuh kembangnya, sehingga Pemberian Makanan Pendamping Air Susu lbu (MP-ASI) sangat diperlukan (Septiana, dkk.,2010).

Faktor yang mempengaruhi status gizi pada bayi, juga dipengaruhi oleh gangguan proses pemberian MP-ASI disebabkan oleh tingkat pendidikan yang rendah yang mengakibatkan kurangnya pengetahuan ibu, kurangnya dukungan dari keluarga dan lingkungan (Arisman, 2010).

Berdasarkan data riskesdas, secara nasional tahun 2013 prevalensi status gizi anak balita menurut (BB/U), (TB/U), dan (BB/TB), yaitu prevalensi gizi buruk sebesar 5,7 \%, dan gizi kurang 13,9\%, prevalensi sangat pendek 0,8 \%, prevalensi pendek 1,2\% prevalensi kurus $0,6 \%$ dan prevalensi gemuk $21 \%$.

Berdasarkan data Profil Kesehatan Sulawesi Tengah tahun 2013 prevalensi status gizi anak balita menurut
(BB/U), (TB/U), dan (BB/TB) yaitu prevalensi gizi buruk sebesar $6,6 \%$, dan gizi kurang $17,5 \%$ prevalensi sangat pendek $17,7 \%$, pendek $23,3 \%$, dan prevalensi sangat kurus $3,6 \%$, kurus sebesar 5,8 \%, gemuk 8,5\%.

Berdasarkan data yang diperoleh dari Puskesmas Pantoloan tahun 2014 prevalensi status gizi anak balita menurut (BB/U), (TB/U), dan (BB/TB), yaitu prevalensi gizi kurang sebesar 9,7\%, gizi buruk 3,9\%, dan gizi lebih 4,1\%, prevalensi pendek $8,6 \%$ dan sangat pendek 3,1\%, prevalensi kurus $12 \%$, sangat kurus $0,8 \%$ dan gemuk $3,2 \%$.

Pendidikan, pekerjaan dan pengetahuan ibu tentang MP-ASI sangat penting dimiliki oleh setiap ibu, karena kurangnya pengetahuan dapat menyebabkan masalah gizi pada anak balita.Berdasarkan uraian diatas, peneliti tertarik untuk meneliti"faktor-faktor yang berhubungan dengan status gizi balita umur 6-23 bulandikelurahan pantoloanboya wilayah kerja puskesmas pantoloan tahun 2015.

\section{METODE PENELITIAN}

Desain penelitian yang digunakan adalah analitik dengan metode crossectional dan pengambilan data menggunkan data primer. Populasi dalam penelitian ini adalah seluruh ibuyang memiliki balita umur 6-23 bulan,dilakukan di Posyandu kelurahan Pantoloan Boya wilayah kerja Puskesmas Pantoloan pada bulan MeiJuni 2015. Sampel dalam penelitian ini menggunakan tehnik accidental sampling yaitu responden yang kebutulan ada atau tersedia disuatu tempat yang berjumlah 76 balita.

\section{HASIL}

Hasil penelitian dalam bentuk data primer diperoleh melalui wawancaralangsung pada responden mengenai pendidikan, pekerjaan dan pengetahuan ibu tentang MP-ASI serta pengukuran status gizi pada balita umur 6-23 bulan.

\section{Analisis Uivariat}


Pada penelitian ini, hasil analisis univariat akan menggambarkan variabel independen yang meliputi pendidikan, pekerjaan dan pengetahuan ibu tentang
MP-ASI serta variable dependen status gizi pada balita umur 6-23 bulan.adalah sebagai

berikut:

Tabel 1

Distribusi Menurut Pendidikan, Pekerjaan, Pengetahuan dan Status Gizi Balita Umur 6-

23 Bulan di Kelurahan Pantoloan Boya Tahun 2015

\begin{tabular}{|c|c|c|c|c|}
\hline No & Variabel & Kategori & $n=76$ & $\%$ \\
\hline 1 & Pendidikan & $\begin{array}{l}\text { Rendah } \\
\text { Tinggi }\end{array}$ & $\begin{array}{l}53 \\
23\end{array}$ & $\begin{array}{l}69,7 \\
30,3\end{array}$ \\
\hline 2 & Pekerjaan & $\begin{array}{l}\text { Tidak Bekerja } \\
\text { Bekerja }\end{array}$ & $\begin{array}{r}73 \\
3 \\
\end{array}$ & $\begin{array}{r}96,1 \\
3,9 \\
\end{array}$ \\
\hline 3 & Pengetahuan & $\begin{array}{l}\text { Kurang Baik } \\
\text { Baik }\end{array}$ & $\begin{array}{l}25 \\
51 \\
\end{array}$ & $\begin{array}{l}32,9 \\
67,1 \\
\end{array}$ \\
\hline 4 & Status Gizi & $\begin{array}{l}\text { Tidak Normal } \\
\text { Normal }\end{array}$ & $\begin{array}{l}14 \\
62 \\
\end{array}$ & $\begin{array}{l}18,4 \\
81,6 \\
\end{array}$ \\
\hline
\end{tabular}

Sumber : Data primer yang diolah

Tabel 1, menunjukkan dari 76 responden yang memiliki pendidikan rendah lebih banyak yaitu 53 responden $(69,7 \%)$ dan yang memiliki pendidikan tinggi yaitu hanya 23 responden (30,3\%). Responden yang tidak bekerja lebih banyak yaitu 73 responden $(96,1 \%)$ sedangkan responden yang bekerja hanya 3 (3,9\%). Responden yang memiliki pengetahuan baik lebih banyak yaitu 45 responden $(67,1 \%)$ dan yang memiliki pengetahuan kurang baik sebanyak 29 responden (32,9\%). Responden yang memiliki balita dengan status gizi normal lebih banyak yaitu 62 $(81,6 \%)$ dan yang tidak normal yaitu 14 responden $(18,6 \%)$.

\section{Analisis Bivariat}

\section{a. HubunganPendidikan Ibu Dengan Status Gizi Balita Umur 6-23 Bulan Di Kelurahan Pantoloan Boya Wilayah Kerja Puskesmas Pantoloan}

Tabel 2

Distribusi Responden Menurut Pendidikan Ibu Dengan Status Gizi Balita Umur 6-23 Bulan Di Kelurahan Pantoloan Boya

\begin{tabular}{|c|c|c|c|c|c|c|}
\hline \multirow{3}{*}{ Pendidikan } & \multicolumn{4}{|c|}{ Status Gizi } & \multirow{3}{*}{$\begin{array}{c}\text { Total } \\
\mathbf{n}\end{array}$} & \multirow{3}{*}{$\begin{array}{c}\text { P value } \\
\text { (Fisher Exact) }\end{array}$} \\
\hline & \multicolumn{2}{|c|}{ Tidak Normal } & \multicolumn{2}{|c|}{ Normal } & & \\
\hline & $\mathbf{f}$ & $\%$ & f & $\%$ & & \\
\hline Rendah & 7 & 13,2 & 46 & 86,8 & 53 & \\
\hline Tinggi & 7 & 30,4 & 16 & 69,6 & 23 & 0,075 \\
\hline Jumlah & 14 & 18,4 & 62 & 81,6 & 76 & \\
\hline
\end{tabular}

Sumber: Data Primer Tahun 2015

Tabel 2 menunjukkan, bahwa ibu yang memiliki pendidikan rendah lebih banyak memiliki balita dengan status gizi normal dengan proporsi $86,8 \%$ dibandingkan yang tidak normal.Sedangkan ibu yang memiliki pendidikan tinggi memiliki balita dengan status gizi normal lebih besar dengan proporsi $69,6 \%$ dibanding dengan yang tidak normal.

Berdasarkan perhitungan nilai expected count setiap kolom yang telah dilakukan, didapatakn lebih dari $20 \%$ kolom yang memiliki nilai expected count< 5, karena penelitian ini mengg8unakan table 
$2 \times 2$ sehingga uji fisher's exact di pilih sebagai uji statistic yang digunakan. Dari hasil uji fishes'r exact didapatkan nilai $p=0,075$ ( $p$ value $>$ 0,05 ) dalam uji statistic apabila $\mathrm{P}>0,05$ menunjukkan bahwa $\mathrm{Ho}$ diterima dan berarti tidak ada hubungan yang bermakna antara pendidikan ibu dengan status gizi balita umur 6-23 bulan di Kelurahan pantoloan Boya Wilayah Kerja Puskesmas Pantoloan.

b. Hubungan Pekerjaan Ibu Dengan Status Gizi Balita Umur 6-23 Bulan Di Kelurahan Pantoloan Boya Wilayah Kerja Puskesmas Pantoloan

Tabel 3

Distribusi Responden Menurut Pekerjaan Ibu Dengan Status Gizi Balita Umur 6-23 Bulan Di Kelurahan Pantoloan Boya

\begin{tabular}{|c|c|c|c|c|c|c|}
\hline \multirow{3}{*}{ Pekerjaan } & \multicolumn{4}{|c|}{ Status Gizi } & \multirow{3}{*}{$\begin{array}{c}\text { Total } \\
\mathbf{N}\end{array}$} & \multirow{3}{*}{$\begin{array}{c}\text { P value } \\
\text { (Fisher Exact) }\end{array}$} \\
\hline & \multicolumn{2}{|c|}{ Tidak Normal } & \multicolumn{2}{|c|}{ Normal } & & \\
\hline & $f$ & $\%$ & $f$ & $\%$ & & \\
\hline Tidak Bekerja & 14 & 19,2 & 59 & 80,8 & 73 & 0,538 \\
\hline Bekerja & 0 & 0 & 16 & 100,0 & 23 & \\
\hline Jumlah & 14 & 18,4 & 62 & 81,6 & 76 & \\
\hline
\end{tabular}

Sumber: Data Primer Tahun 2015

Pada tabel 3 menunjukkan, bahwa ibu yang tidak bekerja lebih banyak memiliki balita dengan status gizi normal dengan proporsi 80,8\% dibandingkan yang tidak normal.Sedangkan ibu yang bekerja memiliki balita dengan status gizi normal lebih besar dengan proporsi $100 \%$ dibanding dengan yang tidak normal.

Berdasarkan perhitungan nilai expected count setiap kolom yang telah dilakukan, didapatakn lebih dari $20 \%$ kolom yang memiliki nilai expected count< 5, karena penelitian ini menggunakan tabel $2 \times 2$ sehingga uji fisher's exact di pilih sebagai uji statistik yang digunakan. Dari hasil uji fishes'r exact didapatkan nilai $p=0,075$ ( $p$ value > $0,05)$ dalam uji statistik apabila $\mathrm{P}>0,05$ menunjukkan bahwa Ho diterima dan berarti tidak ada hubungan yang bermakna antara pekerjaan ibu dengan status gizi balita umur 6-23 bulan di Kelurahan pantoloan Boya Wilayah Kerja Puskesmas Pantoloan.

c. Hubungan Pengetahuan Ibu Dengan Status Gizi Balita Umur 6-23 Bulan Di Kelurahan Pantoloan Boya Wilayah Kerja Puskesmas Pantoloan

Tabel 4

Pendidikan Ibu Dengan Status Gizi Balita Umur 6-23 Bulan Di Kelurahan Pantoloan Boya

\begin{tabular}{|c|c|c|c|c|c|c|}
\hline \multirow{3}{*}{ Pengetahuan } & \multicolumn{4}{|c|}{ Status Gizi } & \multirow{3}{*}{$\begin{array}{c}\text { Total } \\
\mathbf{N}\end{array}$} & \multirow{3}{*}{$\begin{array}{c}\text { P value } \\
\text { (Fisher Exact) }\end{array}$} \\
\hline & \multicolumn{2}{|c|}{ Tidak Normal } & \multicolumn{2}{|c|}{ Normal } & & \\
\hline & $\mathbf{f}$ & $\%$ & $f$ & $\%$ & & \\
\hline Kurang baik & 13 & 52,0 & 12 & 48,0 & 25 & 0,000 \\
\hline Baik & 1 & 2,0 & 50 & 98,0 & 51 & \\
\hline Jumlah & 14 & 18,4 & 62 & 81,6 & 76 & \\
\hline
\end{tabular}


Sumber: Data Primer Tahun 2015

Pada tabel 4 menunjukkan, bahwa ibu yang memiliki pengetahuan kurang baik lebih banyak memiliki balita dengan status gizi tidak normal dengan proporsi $52 \%$ dibandingkan yang normal.Sedangkan ibu yang memiliki pengetahuanbaik memiliki balita dengan status gizi normal lebih besar dengan proporsi 98\% dibanding dengan yang tidak normal.

Berdasarkan perhitungan nilai expected count setiap kolom yang telah dilakukan, didapatakn lebih dari $20 \%$ kolom yang memiliki nilai expected count< 5, karena penelitian ini menggunakan tabel $2 \times 2$ sehingga uji fisher's exact di pilih sebagai uji statistik yang digunakan. Dari hasil uji fishes'r exact didapatkan nilai $p=0,000$ ( $p$ value $<$ $0,05)$ dalam uji statistik apabila $\mathrm{P}>0,05$ menunjukkan bahwa $\mathrm{Ho}$ ditolak dan berarti ada hubungan yang bermakna antara pekerjaan ibu dengan status gizi balita umur 6-23 bulan di Kelurahan pantoloan Boya Wilayah Kerja Puskesmas Pantoloan.

\section{PEMBAHASAN}

1. Hubungan Pendidikan Ibu Dengan Status Gizi Balita Umur 6-23 Bulan Di Kelurahan Pantoloan Boya Wilayah Kerja Puskesmas Pantoloan

Hasil penelitian ini menunjukkan bahwa sebagian besar pendidikan ibu tergolong masih rendah sebesar $69,7 \%$. Hal ini disebabkan karena motivasi yang kurang untuk mendapatkan pendidikan yang lebih baik.Rendahnya pendidikan orang tua khususnya ibu merupakan faktor penyebab mendasar terpenting karena sangat mempengaruhi kemampuan individu, keluarga dan masyarakat dalam mengelola sumber daya yang ada untuk mendapatkan kecukupan bahan mkanan serta sejauh mana pelayanan kesehatan, gizi dan sanitasi lingkungan yang tersedia dimanfaatkan dengan sebaikbaiknya (Depkes RI, 2000). Selanjutnya rendahnya tingkat pendidikan dapat menyebabkan rendahnya pemahaman terhadap apa yang dibutuhkan pada pengasuhan dan perkembangan optimal anak.

Hasil analisa bivariat status gizi berdasarkan pendidikan ibu di Puskesmas Pantoloan Kecamatan Tawaeli Tahun 2014 dengan menggunakan uji fisher's exact menunjukkan bahwa nilai $p$-value sebesar $0,145>0,05$. Hal ini menunjukkan tidak ada hubungan antara pendidikan ibu dengan status gizi balita di puskesmas Pantoloan Kecamatan Tawaeli Tahun 2015.

Hasil Penelitian ini sejalan dengan Suhendri (2009) mendapatkan bahwa tidak ada hubungan antara pendidikan dengan status gizi balita di Puskesmas Sepatan Kecamatan Sepatan Kabupaten Tangerang. Namun penelitian ini tidak sejalan dengan penelitian yang dilakukan oleh Terati,dkk di Kelurahan Kuto Batu Kecamatan Ilir Timur II Kota Palembang Tahun 2011 yang mendapatkan bahwa adanya hubungan antara pendidikan dan status gizi balita 06-60 Bulan.

2. Hubungan Pekerjaan Ibu Dengan Status Gizi Balita Umur 6-23 Bulan Di Kelurahan Pantoloan Boya Wilayah Kerja Puskesmas Pantoloan

Hasil penelitian ini menemukan kecenderungan ibu yang tidak bekerja berpeluang untuk mempunyai anak gizi normal lebih banyak dibandingkan dengan ibu 
yang bekerja.Hal ini disebabkan karena ibu yang tidak bekerja mempunyai kesempatan yang lebih banyak untuk memberikan dan mendampingi balita dalam menyediakan asupan yang lebih baik dan ibu-ibu yang bekerja tidak mempunyai cukup waktu untuk memperhatikan makanan anak yang sesuai dengan kebutuhan dan kecukupan serta kurang perhatian dan pengasuhan kepada anak

Hasil analisa bivariat status gizi berdasarkan pekerjaan ibu di Puskesmas Pantoloan Kecamatan Tawaeli Tahun 2014 dengan menggunakan uji fisher's exactmenunjukkan bahwa nilai $p$ value sebesar 0,538>0,05. Hal ini menunjukkan tidak ada hubungan antara pekerjaan ibu dengan status gizi balita di puskesmas Pantoloan Kecamatan Tawaeli Tahun 2015.

Hasil penelitian ini sejalan dengan hasil penelitian Miko (2003) mendapatkan bahwa proporsi gizi kurang pada anak umur $6-60$ bulan yang mempunyai ibu tidak bekerja lebih banyak $(22,4 \%)$ dibandingkan dengan anak yang mempunyai ibu bekerja $(19,9 \%)$ di Kecamatan Bojongasih Kabupaten Tasikmalaya. Penelitian ini juga sejalan dengan Suhendri (2009) mendapatkan bahwa tidak ada hubungan antara pekerjaan dengan status gizi balita di Puskesmas Sepatan Kecamatan Sepatan Kabuapaten Tangerang.Kusumawati juga mendapatkan bahwa tidak ada hubungan antara pekerjaan dan status gizi balita umur 7-24 bulan. Sedangkan menurut Astuti (2004) yang menganalisa data Susenas tahun 1990 di lima daerah perkotaan, yaitu Medan, Palembang, Bandung, Semarang dan Surabaya, menunjukkan bahwa status pekerjaan ibu berhubungan dengan Mutu Gizi Makanan (MGM). Ibu yang bekerja mempunyai MGM lebih tinggi dibandingkan dengan ibu yang tidak bekerja dan selanjutnya MGM tersebut berdampak terhadap status gizi balita.

\section{Hubungan Pekerjaan Ibu Dengan} Status Gizi Balita Umur 6-23 Bulan Di Kelurahan Pantoloan Boya Wilayah Kerja Puskesmas Pantoloan

Hasil penelitian ini
menunjukan bahwa proporsi pengetahuan ibu yang baik sebesar $67,1 \%$, Pengetahuan yang baik merupakan modal penting untuk ibu balita karena dengan pengetahuan yang baik diharapkan ibu balita dapat memberikan Makanan Pendamping ASI kepada bayinya.

Berdasarkan hasil uji hipotesisi bivariat diperoleh hasil bahwa Ho ditolak $(P<0,05)$ yang mengindikasikan bahwa ada hubungan antara pengetahuan ibu tentang MP-ASI dengan status gizi balita umur 6-23 bulan di Kelurahan Pantoloan Boya Wilayah Kerja Puskesmas Pantoloan tahun 2015.

Pengetahuan merupakan hasil dari tahu dan ini terjadi setelah orang melakukan pengindraan terhadap suatu objek tertentu.Penginderaan terjadi melalui panca indera manusia, yakni indera penglihatan, pendengaran, penciuman, rasa, dan raba.Sebagian besar pengetahuan manusia diperoleh melalui mata dan telinga (Riyanto, 2013).

Faktor yang mempengaruhi pengetahuan diantaranya ada tingkat pendidikan, informasi, budaya, pengalaman, sosial ekonomi (Notoadmojo, 2007).

Pengetahuan ibu adalah suatu faktor yang penting dalam pemberian makanan tambahan pada bayi karena dengan pengetahuan yang baik, ibu tahu kapan waktu pemberian makanan 
yang tepat. Pengetahuan dapat diperoleh dari informasi yang disampaikan orang lain, media cetak, media elektronik, atau penyuluhan-penyuluhan.

Pengetahuan didukung oleh pendidikan karena pendidikan merupakan suatu proses untuk mengenbangkan semua aspek kepribadian manusia, meliputi pengetahuan, nilai sikap, dan ketrampilan sehingga terjadi perubahan perilaku yang positif. Ketidaktahuan tentang akibat pemberian makanan pendamping ASI dini dan cara pemberiannya serta kebiasaan yang merugikan kesehatan, secara langsung ataupun tidak secara langsung menjadi penyebab masalah gizi kurang pada anak, khususnya pada anak usia dibawah 2 tahun (Aryani, 2008 dalam Dewanti .T 2009).

$$
\text { Selain itu Tingkat }
$$

pendidikan sangat berpengaruh terhadap tingkat pengetahuan.Pendidikan

mempunyai peranan penting dalam pembentukan kecerdasan manusia maupun perubahan tingkah lakunya.Tidak dapat dipungkiri bahwa semakin tinggi pendidikan seseorang maka semakin mudah pula mereka menerima informasi. Pada akhirnya banyak pula pengetahuan yang dimilikinya, sebaliknya jika seseorang memiliki tingkat pendidikan yang rendah maka akan menghambat perkembangan sikap seseorang terhadap penerimaan informasi (Mubarak\& Chayatin, 2009). Kemudian Tingkat pendidikan ibu menunjukkan berpendidikan tinggi yaitu SMP, SMA dan perguruan tinggi. Dalam penelitian ini masih terdapat ibu yang berpendidikan rendah yaitu $\mathrm{SD}$, hal ini yang menyebabkan kemampuan ibu dalam menyerap informasi yang diterima kurang dimengerti terhadap informasi yang diberikan sehingga dalam penelitian pengisian jawaban kuesioner ibu sering bertanya karena tidak tahu, berbeda dengan ibu yang berpendidikan SMP, SMA dan perguruan tinggi lebih mudah menerima informasi yang diterima karena pendidikan yang relatif baik.

Responden sebagian besar ibu rumah tangga (IRT) sebanyak 73 responden (96\%) menjadikan ibu cenderung lebih memperhatikan kebutuhan keluarga sehingga ibu dapat mengurus anaknya secara langsung.lbu juga lebih banyak memperoleh informasi dan penyuluhan untuk meningkatkan pengetahuan tentang gizi terutama makanan pendamping ASI. Penyuluhan tentang gizi diberikan oleh petugas Puskesmas secara khusus kepada ibu-ibu yang memiliki anak dengan status gizi buruk atau kurang dengan frekuensi penyuluhan satu bulan sekali di Puskesmas

Pengetahuan Makanan

Pendamping ASI perlu diketahui oleh seorang ibu, karena jika anak tidak mendapat makanan pendamping ASI dengan tepat dan benar, maka akan berdampak terhadap status gizi. Makanan almiah tebaik bagi bayi yaitu Air Susu Ibu (ASI). Sesudah usia enam bulan anak akan mendapatkan makanan pendamping ASI dengan tepat dan benar baik jumlah maupun kualitasnya (Nency\& Arifin, 2005)

\section{KESIMPULAN}

1. Tidak ada hubungan antara pendidikan ibu dengan status gizi balita umur 6-23 bulan di Kelurahan Pantoloan Boya Wilayah Kerja Puskesmas Pantoloan

2. Tidak ada hubungan antara pekerjaan ibu dengan status gizi balita umur 6-23 bulan di Kelurahan Pantoloan Boya Wilayah Kerja Puskesmas Pantoloan 
3. Ada hubungan antara pengetahuan ibu tentang MP-ASI dengan status gizi balita umur 6-23 bulan di Kelurahan Pantoloan Boya Wilayah Kerja Puskesmas Pantoloan

\section{SARAN}

1. Bagi petugas kesehatan Puskesmas Pantoloan untuk lebih proaktif dalam memberikan penyuluhan kepada ibu-ibu balita, khususnya mengenai MP-ASI dan Status Gizi. Sehingga ibu-ibu memiliki pengetahuan yang lebih baik.

2. Bagi peneliti berikutnya diharapkan dapat melanjutkan penelitian ini dengan variabel yang lebih luas.

\section{DAFTAR PUSTAKA}

Almatsier, S.2009. Prinsip Dasar IImu Gizi. Jakarta : Gramedia Pustaka Utama.

Arisman, 2011.Gizi Dalam Daur Kehidupan. Penerbit Buku Kedokteran EGC.

Astuti, Rahayu 2004. Peran Penyakit Infeksi, Sosial Ekonomi dan Sanitasi Lingkungan Dalam Mempengaruhi Status Gizi Balita di Pedesaan Provinsi Jawa Tengah Tahun 2002. Tesis FKM UI. Depok 2004

Depkes RI, 2000. Rencana Aksi Pangan dan Gizi Nasional. Jakarta

Dewanti, T. 2009. Hubungan Tingkat Pengetahuan Ibu Tentang Makanan Pendamping ASI dengan Perubahan Berat Badan Balita Usia 6-24 bulandi Posyandu Desa Banjarsari Kecamatan Gajah Kabupaten Demak.Skripsi.Universitas Diponegoro. Semarang.

Dinkes Sulteng , 2013.Profil Kesehatan Lengkap. Dinas Kesehatan Provinsi Sulawesi

Kemenkes, 2011.Pedoman Pelayanan Anak Gizi Buruk. Jakarta : Kementerian Kesehatan RI
Miko, Hadiyat, 2003. Faktor-Faktor Yang Berhubungan Dengan Status Gizi (KEP) Anak Umur 6-60 Bulan Di Kecamatan Bojongasih Kabupaten Tasikmalaya Tahun 2002.Depok : Tesis FKM UI. 2003.

Mubarak, W.I., Chayatin, N., 2009. IImu Kesehatan Masyarakat Teori dan Aplikasi.Jakarta : Salemba Medika.

Nency Y, Arifin M.T., 2005. Gizi Buruk Ancaman Generasi yang Hilang.Diakses tanggal 13 Januari 2015,http://ppi-jepang.org.

Notoadmojo, S, 2007. Kesehatan Masyarakat IImu dan Seni.Jakarta : PT Rineka Cipta.

Puskesmas Pantoloan, 2014. Profil Kesehatan Puskesmas Pantoloan, Puskesmas Pantoloan

Riyanto, A \& Budiman, 2013.Kapita Selekta Kuesioner Pengetahuan Dan Sikap Dalam Penelitian Kesehatan. Jakarta : Penerbit Salemba Medika.

Septiana, R, Djannah, R \& Djamil, M. 2010.Hubungan Antara Pola Pemberian Makanan Pendamping Asi (MP-ASI) Dan Status Gizi Balita Usia 6-24

Bulan.http://www.acamedia.edu/834 4704.pdf.Diakses pada tanggal 2 Januari 2015

Suhendri, Ucu. 2009. Faktor-faktor yang berhubungan dengan status gizi anak dibawah lima tahun (balita) di puskesmas Sepatan Kecamatan Sepatan Kabupaten Tanggerang tahun 2009. Skripsi. Fakultas Kedokteran dan IImu Kesehatan Universitas Islam Negri Syarif Hidayatullah. Jakarta. Tengah

Terati, Nilawati N.S., Fatonah R.D., (2011)Faktor-Faktor Yang Berhubungan DenganStatus Gizi Balita Usia 06-60 Bulan Di Kelurahan KutoBatu Kecamatan Ilir Timur li Kota Palembang Tahun 2011. 